\title{
Negative emotions about climate change are related to insomnia symptoms and mental health: Cross-sectional evidence from 25 countries
}

\author{
Charles Adedayo Ogunbode ${ }^{1,2}$ (D) Ståle Pallesen ${ }^{3} \cdot$ Gisela Böhm ${ }^{3,4} \cdot$ Rouven Doran $^{3} \cdot$ Navjot Bhullar $^{5}$. \\ Sibele Aquino ${ }^{6}$. Tiago Marot ${ }^{6}$. Julie Aitken Schermer ${ }^{7}$. Anna Wlodarczyk ${ }^{8}$. Su Lu ${ }^{2}$. Feng Jiang ${ }^{9}$. \\ Katariina Salmela-Aro ${ }^{10}$. Daniel Hanss ${ }^{11}$ - Daniela Acquadro Maran ${ }^{12}$ - Rahkman Ardi ${ }^{13}$ Razieh Chegeni $^{3}$. \\ Hajra Tahir ${ }^{3}$. Elahe Ghanbarian ${ }^{14}$. Joonha Park ${ }^{15}$. Takashi Tsubakita ${ }^{15}$. Chee-Seng Tan ${ }^{16}$. \\ Karlijn L. van den Broek ${ }^{17,18}$. JohnBosco Chika Chukwuorji ${ }^{19}$ - Kehinde Ojewumi ${ }^{20}$ Marc Eric S. Reyes $^{21}$. \\ Samuel Lins ${ }^{22}$ • Violeta Enea ${ }^{23}$ - Tatiana Volkodav ${ }^{24}$. Tomas Sollar ${ }^{25}$. Ginés Navarro-Carrillo ${ }^{26}$. \\ Jorge Torres-Marín ${ }^{27} \cdot$ Winfred Mbungu $^{28} \cdot$ Charles Onyutha $^{29} \cdot$ Michael J. Lomas $^{30}$
}

Accepted: 14 January 2021 / Published online: 16 February 2021

(C) The Author(s) 2021

\begin{abstract}
Climate change threatens mental health via increasing exposure to the social and economic disruptions created by extreme weather and large-scale climatic events, as well as through the anxiety associated with recognising the existential threat posed by the climate crisis. Considering the growing levels of climate change awareness across the world, negative emotions like anxiety and worry about climate-related risks are a potentially pervasive conduit for the adverse impacts of climate change on mental health. In this study, we examined how negative climate-related emotions relate to sleep and mental health among a diverse non-representative sample of individuals recruited from 25 countries, as well as a Norwegian nationally-representative sample. Overall, we found that negative climate-related emotions are positively associated with insomnia symptoms and negatively related to self-rated mental health in most countries. Our findings suggest that climate-related psychological stressors are significantly linked with mental health in many countries and draw attention to the need for cross-disciplinary research aimed at achieving rigorous empirical assessments of the unique challenge posed to mental health by negative emotional responses to climate change.
\end{abstract}

Keywords Climate anxiety $\cdot$ Emotions $\cdot$ Insomnia $\cdot$ Mental health $\cdot$ Climate change $\cdot$ Eco-anxiety

\section{Introduction}

Climate change has important implications for mental health. These implications may arise from the physical, social and economic impacts of extreme and acute climatic changes or the psychological distress and anxiety evoked by awareness of the short- and long-term impacts of climate change (Cunsolo \& Ellis, 2018; Fritze, Blashki, Burke, \& Wiseman, 2008; Hayes, Blashki, Wiseman, Burke, \& Reifels, 2018). Previously, research has strongly focused on how direct exposure to adverse environmental conditions such as high

Charles Adedayo Ogunbode

charles.ogunbode@nottingham.ac.uk

Extended author information available on the last page of the article temperatures, drought, and flooding affect mental health (Burke et al., 2018; Evans, 2019; Graham, White, Cotton, \& McManus, 2019; Obradovich, Migliorini, Paulus, \& Rahwan, 2018). Yet, for most people, exposure to climate change is indirect; occurring via media representations of ongoing environmental changes and impacts occurring around the world (Doherty, 2018; Doherty \& Clayton, 2011). Given the growing rates of media coverage of climate change in many countries (Schmidt, Ivanova, \& Schäfer, 2013), rising public consciousness of the risks posed by climate change, rather than direct exposure to unfavourable environmental conditions, is likely to be a pervasive pathway by which climate change affects mental health.

Presently, a large majority of people across the world see climate change as a major threat and are worried about its projected consequences (Fagan \& Huang, 2019; Gustafson, Bergquist, Leiserowitz, \& Maibach, 2019). Worry about 
climate change is an important determinant of proenvironmental actions and support for climate policies (Smith \& Leiserowitz, 2014; Wang, Leviston, Hurlstone, Lawrence, \& Walker, 2018), but it is also associated with psychological distress (Searle \& Gow, 2010). The concept of climate change anxiety has recently gained prominence in discussions of the various negative emotions, including worry, that people are experiencing in response to climate change (Clayton, 2020; Clayton \& Karazsia, 2020). While climate change anxiety has been the subject of considerable media attention, there is a dearth of empirical evidence regarding how such negative emotions relate to mental health. Further, although negative impacts on mental health are recognised as a part of a range of intangible harms inflicted globally by climate change (Tschakert, Ellis, Anderson, Kelly, \& Obeng, 2019), the current discourse regarding climate change anxiety has largely centred on its manifestation in Western countries (BBC, 2019b, 2020; Clayton \& Karazsia, 2020; Nugent, 2019). Consequently, the significance of negative climaterelated emotions for mental health remains unclear in a global context. In the present study, we conducted a cross-national empirical investigation of the relationship between negative climate-related emotions and mental health, with an additional focus on how negative climate-related emotions relate to sleep.

Climate change anxiety is often used interchangeably with the broader concept of eco-anxiety, which is defined as a chronic fear of ecological doom (Albrecht, 2011; Clayton, Manning, Krygsman, \& Speiser, 2017). The accounts provided by individuals living with climate change anxiety support a definition of the phenomenon as a profound negative emotional response to anticipated trauma (BBC, 2019b; Bednarek, 2019). People affected by climate change anxiety commonly speak of emotional distress evoked by perceived negative changes in valued physical and natural spaces (Kielland \& Larssen, 2019), a paralysing fear of the end of the world (BBC, 2019b), and of a deep sense of despair about how future generations may be harmed by climate change (BBC, 2019a). Anxiety about a future Earth made unliveable by climate change is also linked to a growing number of individuals deciding not to have children (Hunt, 2019; SchneiderMayerson \& Leong, 2020). With the growing frequency of abnormal weather and climatic events attributed to global climate change, scholars suggest that climate-related negative emotions can be expected to have a significant impact on mental health, even among people who are not directly exposed to these climatic events (Clayton \& Karazsia, 2020).

Many negative mental health outcomes associated with climate change may be theoretically linked with sleep (Obradovich \& Migliorini, 2018). Sleep problems are a common cause and symptom of various mental health disorders, including affective and anxiety disorders (Baglioni et al., 2016). The role of sleep in mental health disorders is partly attributed to a reciprocal relationship between sleep and emotion dysregulation, whereby high negative emotional arousal leads to sleep disturbance, which can in turn amplify negative emotional responses to stress-inducing stimuli (Harvey, Murray, Chandler, \& Soehner, 2011). Previously, sleep has not figured strongly in the climate change literature. However, there is some indication that climate change has significant impacts on sleep quality. A recent review of the literature reports that rising temperatures and extreme weather events, particularly hurricanes, flooding and wildfires are linked to sleep disruption and diminished sleep duration (Rifkin, Long, \& Perry, 2018). According to Obradovich, Migliorini, Mednick, and Fowler (2017), a $1{ }^{\circ} \mathrm{C}$ rise in monthly nighttime temperatures is associated with an increase of three nights of insufficient sleep per 100 people in the United States. Zhen, Quan, and Zhou (2018) also showed that traumatic exposure to flooding is associated with sleep problems, and that this association is mediated by fear and depression. Negative emotions regarding climate change have yet to be empirically linked to sleep, but evidence of a link between negative emotions and sleep problems is strongly established (Baglioni, Spiegelhalder, Lombardo, \& Riemann, 2010). In light of this literature, we anticipate that negative climaterelated emotions are associated with sleep problems.

The primary aim of this study was to determine how negative climate-related emotions relate to mental health across a broad range of national contexts extending beyond Western countries. We hypothesized that negative climate-related emotions will be negatively related to mental health (H1) and positively related to sleep problems (H2). Sleep problems were operationalised in the study using an index of insomnia symptoms.

\section{Method}

\section{Data}

We tested our hypotheses using data from two large crosssectional questionnaire surveys. The first survey, conducted in autumn 2019, involved a diverse sample of individuals from 25 countries spanning all the inhabited continents $(N=$ 10,$143 ; M_{\text {age }}=23.4$ years, $S D_{\text {age }}=7.3$, Males $=33.7 \%$, Females $=63.4 \%$ ). Respondents were recruited from university research participant pools using opportunity sampling. In non-English speaking countries, the questionnaire was translated into local languages by competent bilingual speakers using the translation-back-translation method (Brislin, 1970). Ethics approval for the survey was granted by the De Montfort University University, Health and Life Sciences Faculty Research Ethics Committee (FREC; ref.: 3434).

The second survey was conducted in spring 2020 with a representative sample of residents in Norway $(N=1015$; 
$M_{\text {age }}=46.3$ years, $S D_{\text {age }}=17.5$, Males $=47.7 \%$, Females $=$ $52.3 \%$ ). The respondents were recruited via a commercial research panel provider. The design and administration of the survey was fully compliant with the British Psychological Association code of Research Ethics and Conduct (BPS, 2018). Participants in the two surveys were provided with information about the nature of the study, including how the data were to be used, and asked to indicate their consent to participate before proceeding to complete the questionnaire. Full demographic information for the samples recruited in both surveys is provided as supplementary data (Tables 1 and 2, File S1).

\section{Measures}

Research participants in both surveys completed a questionnaire including items measuring negative climate-related emotions, insomnia symptoms and self-rated mental health.
Negative climate-related emotions were measured with a 7item index loosely based on the state anxiety component of the State-Trait Anxiety Inventory (Spielberger, 1983). Participants were instructed to collect their thoughts and focus on their feelings about climate change, after which they were directed to rate how much they feel calm, tense, relaxed, anxious, peaceful, worried and terrified about climate change at the present moment. Ratings for each item were recorded using a 5-point scale ranging from 1 (not at all) to 5 (extremely). Responses to the 'calm', 'relaxed' and 'peaceful' items were reversed prior to analysis. The scale showed adequate internal consistency across all the countries surveyed with Cronbach's $\alpha$ values ranging from .72 to .92 (Table 1).

Insomnia symptoms were measured with the Bergen Insomnia Scale (Pallesen et al., 2008). This scale has previously been validated against subjective and polysomnographic data and across various cultural groups (Bay \& Ergun, 2018; Naher, Johora, Alam, \& Ahmed, 2019; Pallesen et al., 2008). Examples of items included in the scale are: 'During
Table 1 Descriptive and reliability statistics for measured variables (negative climaterelated emotions, insomnia symptoms and self-rated mental health)

\begin{tabular}{|c|c|c|c|c|c|}
\hline \multirow[t]{2}{*}{ Country } & \multicolumn{2}{|c|}{ Negative climate-related emotions } & \multicolumn{2}{|c|}{ Insomnia symptoms } & \multirow[t]{2}{*}{ Mental health } \\
\hline & $\mathrm{M}(\mathrm{SD})$ & $\alpha$ & $\mathrm{M}(\mathrm{SD})$ & $\alpha$ & \\
\hline Australia & $3.22(0.91)$ & 0.90 & $3.33(1.78)$ & 0.86 & $3.01(1.12)$ \\
\hline Brazil & $3.76(0.91)$ & 0.91 & $3.32(1.57)$ & 0.78 & $2.78(0.99)$ \\
\hline Canada & $3.12(0.78)$ & 0.88 & $3.30(1.53)$ & 0.80 & $2.93(1.01)$ \\
\hline Chile & $3.31(0.74)$ & 0.83 & $3.60(1.72)$ & 0.83 & $2.50(1.05)$ \\
\hline China & $2.86(0.81)$ & 0.89 & $2.71(1.42)$ & 0.78 & $3.05(0.97)$ \\
\hline Finland & $3.26(0.96)$ & 0.92 & $2.53(1.40)$ & 0.79 & $2.96(1.01)$ \\
\hline Germany & $3.39(0.84)$ & 0.87 & $2.54(1.42)$ & 0.81 & $3.04(0.92)$ \\
\hline Italy & $3.41(0.73)$ & 0.89 & $3.13(1.52)$ & 0.83 & $3.08(0.82)$ \\
\hline Indonesia & $3.32(0.68)$ & 0.84 & $3.69(1.32)$ & 0.71 & $2.49(0.86)$ \\
\hline Iran & $3.32(0.84)$ & 0.86 & $2.59(1.27)$ & 0.64 & $3.07(1.01)$ \\
\hline Japan & $3.05(0.65)$ & 0.73 & $2.39(1.33)$ & 0.73 & $2.62(1.09)$ \\
\hline Malaysia & $3.06(0.71)$ & 0.86 & $2.74(1.52)$ & 0.80 & $3.03(0.89)$ \\
\hline Netherlands & $3.20(0.78)$ & 0.88 & $2.42(1.41)$ & 0.81 & $3.06(1.03)$ \\
\hline Nigeria & $2.84(0.73)$ & 0.71 & 3.17 (1.44) & 0.81 & $3.53(0.98)$ \\
\hline Norway & $3.09(0.81)$ & 0.87 & $2.32(1.40)$ & 0.81 & $3.20(1.04)$ \\
\hline Pakistan & $3.03(0.80)$ & 0.81 & $3.85(1.54)$ & 0.84 & $2.80(0.97)$ \\
\hline Philippines & $3.55(0.73)$ & 0.85 & $4.03(1.44)$ & 0.73 & $2.82(0.96)$ \\
\hline Portugal & $3.43(0.77)$ & 0.87 & $3.64(1.48)$ & 0.83 & $3.02(0.95)$ \\
\hline Romania & $2.90(0.84)$ & 0.86 & $2.83(1.44)$ & 0.80 & $3.33(0.99)$ \\
\hline Russia & $2.71(0.62)$ & 0.75 & $2.96(1.64)$ & 0.76 & $3.19(0.97)$ \\
\hline Slovakia & $3.00(0.77)$ & 0.83 & $3.25(1.48)$ & 0.79 & $3.17(0.94)$ \\
\hline Spain & $3.66(0.72)$ & 0.86 & $2.72(1.56)$ & 0.83 & $2.86(1.00)$ \\
\hline Tanzania & $2.91(0.72)$ & 0.75 & $3.38(1.40)$ & 0.73 & $3.74(0.97)$ \\
\hline Uganda & $3.18(0.87)$ & 0.84 & $3.22(1.47)$ & 0.76 & $3.43(0.93)$ \\
\hline United Kingdom & $3.26(0.80)$ & 0.88 & $3.84(1.53)$ & 0.80 & $2.67(1.07)$ \\
\hline Total & $3.23(0.83)$ & 0.86 & $3.18(1.58)$ & 0.80 & $3.01(1.03)$ \\
\hline Norway (Representative) & $2.50(0.76)$ & 0.88 & $2.12(1.60)$ & 0.83 & $3.39(1.11)$ \\
\hline
\end{tabular}


Table 2 Multilevel models of negative climate-related emotions, insomnia symptoms and mental health

\begin{tabular}{|c|c|c|c|c|}
\hline & \multicolumn{2}{|c|}{ Insomnia symptoms } & \multicolumn{2}{|l|}{ Mental health } \\
\hline & Estimate $(\mathrm{SE})^{\dagger}$ & $95 \% \mathrm{CI}$ & Estimate (SE) & $95 \% \mathrm{CI}$ \\
\hline \multicolumn{5}{|l|}{ Fixed effects } \\
\hline Negative climate-related emotions & $0.25(0.02)^{*}$ & $0.21,0.28$ & $-0.24(0.013)^{*}$ & $-0.27,-0.22$ \\
\hline Age & $-0.01(0.00)^{*}$ & $-0.02,-0.01$ & $0.01(0.00)^{*}$ & $0.00,0.01$ \\
\hline Gender (Female) & $0.19(0.03)^{*}$ & $0.12,0.25$ & $-0.13(0.02)^{*}$ & $-0.18,-0.09$ \\
\hline Intercept & $3.11(0.10)^{*}$ & $2.91,3.30$ & $3.01(0.05)^{*}$ & $2.91,3.11$ \\
\hline Random effects & Variance & Std. dev. & Variance & Std. dev. \\
\hline Country (intercept) & 0.23 & 0.48 & 0.06 & 0.25 \\
\hline AIC & \multicolumn{2}{|l|}{$34,924.2$} & \multicolumn{2}{|l|}{$26,824.0$} \\
\hline Marginal $R^{2}$ & \multicolumn{2}{|l|}{0.03} & \multicolumn{2}{|l|}{0.05} \\
\hline Conditional $R^{2}$ & \multicolumn{2}{|l|}{0.12} & \multicolumn{2}{|l|}{0.11} \\
\hline$N$ & \multicolumn{2}{|l|}{9683} & \multicolumn{2}{|l|}{9705} \\
\hline
\end{tabular}

$* p<.001, \dagger$ Estimates are linear coefficients the past month, how many days a week has it taken you more than 30 minutes to fall asleep after the light was switched off?' and 'During the past month, how many days a week have you been awake for more than 30 minutes between periods of sleep?'. The Bergen Insomnia Scale comprises a total of six items. It showed acceptable levels of internal consistency across countries with Cronbach's $\alpha$ values ranging from .64 to .86 (Table 1).

Self-rated mental health was measured with a single-item scale adopted from the mental health supplement of the Ontario Health Survey (see Ahmad, Jhajj, Stewart, Burghardt, \& Bierman, 2014). Participants were instructed to rate their overall mental health on a 5 -point scale $(1=$ poor, 2 = fair, 3 = good, 4 = very good, $5=$ excellent).

\section{Analysis}

Relationships between negative climate-related emotions, insomnia symptoms and mental health across countries were initially assessed in the cross-national data using correlation analysis. Due to the nested nature of the data (individuals within countries), linear multilevel regression models with random intercepts were estimated using the $\mathrm{R}$ package lme4 (Bates, Maechler, Bolker, \& Walker, 2014) to test our hypotheses. Level 1 fixed effects were negative climate-related emotions, age and gender. At level 2, we modelled participants' country as random effects (intercepts). All independent variables were grand mean centred.

In the first stage of model building, we estimated an unconstrained model with no level 1 predictors. This null model was used to estimate the intraclass coefficient (ICC). The null model showed a significant amount of variance in insomnia symptoms $\left(\gamma_{00}=3.10, t(25.05)=31.44, p<.001\right)$ and mental health $\left(\Upsilon_{00}=3.01, t(25.04)=51.39, p<.001\right)$ across the data.
The random effects part of the model showed a substantial degree of within-country $\left(\tau_{00}=2.20\right)$ and between-country $(\sigma=.24)$ variance for insomnia symptoms, yielding an intraclass coefficient $\rho=0.10$. Similarly, we observed substantial within-country $\left(\tau_{00}=0.97\right)$ and between-country $(\sigma=.08)$ variance in self-rated mental health, which yielded a $\rho=0.08$. These ICC estimates mean that around $10 \%$ of the variance in insomnia symptoms and $8 \%$ of the variance in mental health is explained by participants' country. In other words, participants from the same country are more similar in their insomnia symptoms and self-rated mental health scores than participants from different countries. Although, these ICC values are somewhat smaller than those been obtained in other cross-cultural research in environmental psychology (e.g., Schultz et al., 2014), we concluded that there is a clustering effect in our data and we cannot treat scores within countries as independent. Thus, the use of a multilevel approach to our hypothesis testing was justified.

There was a small amount of missing data in the cross-national survey $(<5 \%)$. List-wise deletion was applied in all our analyses. For the purpose of comparisons across Western and non-Western countries, we used the following classification: Australia, Brazil, Canada, Chile, Finland, Germany, Italy, Netherlands, Norway, Portugal, Spain and the United Kingdom were classed as Western countries while China, Indonesia, Iran, Japan, Malaysia, Nigeria, Pakistan, Philippines, Romania, Russia, Slovakia, Tanzania and Uganda were classed as nonWestern countries.

Our hypotheses were further tested with data from the Norwegian representative survey using weighted least squares regression. The main purpose of the Norwegian data analysis was to determine the degree to which the findings from the cross-national sample replicate in the absence of sampling 
biases such as the overrepresentation of females, young respondents and university students. Here, we also included age and gender as covariates.

\section{Results}

\section{Cross-National Survey}

Negative climate-related emotions were positively correlated with insomnia symptoms $(r$ pooled $=0.16, p<.001, N=$ $10,098)$ across all 25 countries represented in the crossnational survey (Fig. 1). This relationship was significant at the conventional significance threshold of $p<.05$ in all countries except China, Italy, Japan, Malaysia, Norway, Slovakia and Tanzania. Negative climate-related emotions were inversely correlated with mental health across the crossnational data $(r$ pooled $=-0.24, p<.001, N=10,131)$ but this correlation was not significant in Italy, Japan, Malaysia and Tanzania. The correlation between negative climate-related emotions and insomnia symptoms in Western countries $(r$ pooled $=0.18, p<.001, N=4336)$ and non-Western countries $(r$ pooled $=0.17, p<.001, N=5763)$ was roughly equivalent $(z=0.51, p=.608)$. However, the correlation between negative climate-related emotions and self-rated mental health was different in Western countries $(r$ pooled $=-0.25, p<.001, N=$ 4361) compared with non-Western countries $\left(r_{\text {pooled }}=-0.21\right.$, $p<.001, N=5756$ ), with this correlation being significantly stronger in Western countries $(z=-2.10, p=.035)$.

In line with the correlation analysis, the multilevel regression models revealed that negative climate-related emotions

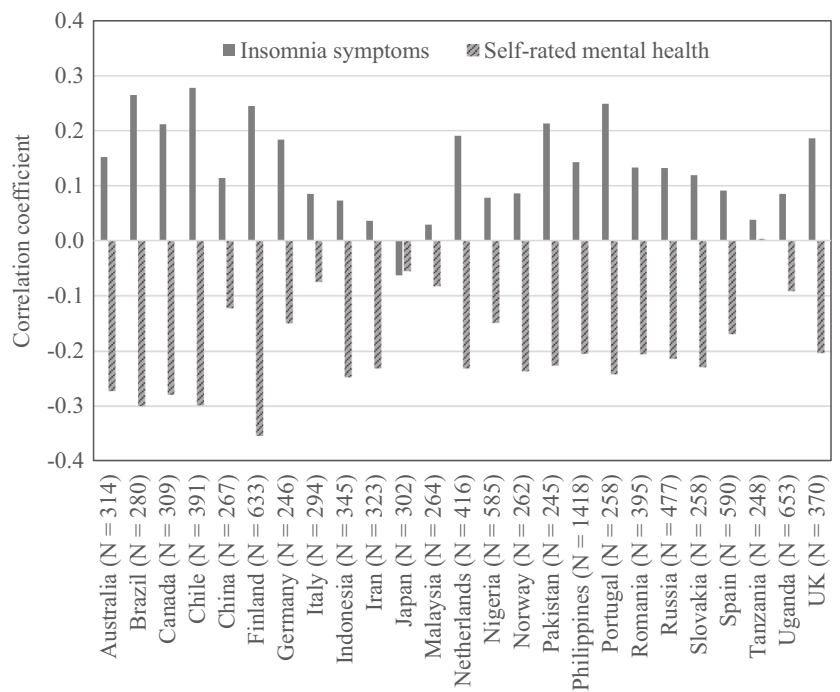

Fig. 1 Cross-national zero-order associations of negative climate-related emotions with insomnia symptoms and self-rated mental health. Estimates are Pearson product moment correlation coefficients positively predicted insomnia symptoms and negatively predicted mental health (Table 2). Further, insomnia symptoms were inversely related to age and positively related with gender. Female respondents reported higher levels of insomnia symptoms on average. Age and gender were also significantly related with self-rated mental health, whereby older respondents reported better mental health and females reported poorer mental health on average. Using the 'MuMIn' package for R (Barton, 2013), we estimated that the level 1 fixed effects: negative climate-related emotions, age and gender, explained around $3 \%$ and $5 \%$ of the variance in insomnia symptoms and self-rated mental health respectively.

\section{Norwegian Representative Survey}

The overall pattern of correlations observed across the crossnational data was replicated with the Norwegian representative data where we observed a significant positive correlation between negative climate-related emotions and insomnia symptoms $(r=0.17, p<.001, N=1015)$ and a negative correlation between negative climate-related emotions and selfrated mental health $(r=-0.16, p<.001, N=1015)$. We tested our hypotheses using weighted least squares regression and including participants' age and gender as covariates. The results revealed that negative climate-related emotions were positively related to insomnia symptoms $(\mathrm{H} 1)$ and negatively related to mental health $(\mathrm{H} 2)$ among the Norwegian nationally-representative sample (Table 3). Further, age was negatively related to insomnia symptoms and positively related to mental health, while gender was only significantly related to insomnia symptoms. Similar to the cross-national sample, females in the Norwegian nationally-representative sample reported greater insomnia symptoms than males.

\section{Discussion}

The primary purpose of this study was to determine how negative emotions regarding climate change relate to mental health in a global context. Based on the trends observed across non-representative samples of individuals from 25 countries and one nationally-representative sample from Norway, our data show that negative climate-related emotions have a modest but consistent negative relationship with a subjective measure of mental health around the world. In most countries surveyed, negative climate-related emotions showed a significant positive correlation with insomnia symptoms ( $72 \%$ of the countries), and a significant negative correlation with selfrated mental health ( $84 \%$ of the countries). This indicates that negative emotions regarding climate change have relevance for mental health at a global level. 
Table 3 Insomnia symptoms and mental health regressed on negative climate-related emotions

\begin{tabular}{|c|c|c|c|c|}
\hline & \multicolumn{2}{|c|}{ Insomnia symptoms } & \multicolumn{2}{|l|}{ Mental health } \\
\hline & $\mathrm{B}(\mathrm{SE})$ & Sig. & $\mathrm{B}(\mathrm{SE})$ & Sig. \\
\hline Negative climate-related emotions & $0.26(.07)$ & $<.001$ & $-0.19(0.04)$ & $<.001$ \\
\hline Age & $-0.01(0.00)$ & $<.001$ & $0.01(0.00)$ & $<.001$ \\
\hline Gender (Female) & $0.44(0.10)$ & $<.001$ & $-0.10(0.07)$ & .146 \\
\hline$F$ & 19.74 & $<.001$ & 18.05 & $<.001$ \\
\hline Adj. $R^{2}$ & .05 & & .05 & \\
\hline$N$ & 1015 & & 1015 & \\
\hline
\end{tabular}

Cell entries are unstandardised linear regression estimates

\section{Implications}

The continuing consolidation of scientific evidence of the dangerous near- and long-term implications of unabated global warming, such as is presented in the 2018 IPCC special report on $1.5^{\circ} \mathrm{C}$ global warming, fosters heightened public concern and perceived threat from climate change (Ogunbode, Doran, \& Böhm, 2020). Escalating public concerns about climate change were recently evidenced by the widespread protests witnessed globally in 2019 involving millions of children, youth and adults calling for an urgent societal response to the emerging climate crisis. However, negative emotions about the anticipated consequences of climate change may not only serve to galvanise mass climate action. Our data suggest that negative emotions regarding climate change may also undermine mental health and cause people to lose sleep, which is itself a key component of healthy psychological functioning and wellbeing.

This study is the first to examine the relationship between climate change-related emotions and mental health with crossnational data that captures a broad range of cultural backgrounds. We observed that negative climate change-related emotions have a slightly stronger correlation with self-rated mental health in Western countries compared with nonWestern countries, but the magnitude of the correlation between negative climate change-related emotions and insomnia symptoms was equivalent across the two categories of countries. Possibly, this reflects differences in the precision of the measures used to capture mental health and insomnia symptoms in the study. The self-rated mental health measure opens the door to a degree of ambiguity by allowing respondents define what they subjectively understand as constituting their mental health. Lay understandings of mental health differ significantly across cultural groups (Giosan, Glovsky, \& Haslam, 2001), and the subjective understandings of mental health and negative emotions may be more conceptually proximate among Western individuals than non-Western individuals. However, the index of insomnia symptoms is less ambiguous and the equivalence of the relationship between negative climate-related emotions and insomnia symptoms across Western and non-Western countries has important implications for further research on climate change and mental health.

Although climate change anxiety is not currently classified as a mental health disorder, dysregulated negative emotional responses to environmental problems can significantly impair individuals' health and psychological functioning (Clayton, 2020). Sleep disturbance is a common symptom of a wide range of mental ill-health conditions (Harvey et al., 2011). Given the equivalent relationship between negative climaterelated emotions and insomnia symptoms observed across Western and non-western countries in this study, and the previously established relationship between sleep disturbance and poor mental health, we suggest that sleep disturbance or insomnia symptoms may be considered a cross-culturally diagnostic index of mental health-threatening negative emotional responses to climate change.

There is already a great deal of evidence that climate change affects mental health directly through natural disasters and gradual environmental changes. For example, communities affected by ecological disasters such as hurricanes, flooding, droughts and wildfires show increased rates of post-traumatic stress disorder (PTSD), anxiety, depression and substance abuse (Morganstein \& Ursano, 2020). Rising temperatures have also been linked with increased rates of suicide and hospitalisation for mental health problems (Burke et al., 2018; Carleton, 2017; Obradovich et al., 2018). However, our findings reinforce an understanding that climate change poses a challenge for mental health through other channels than direct exposure to impacts from biophysical phenomena. Negative emotions arising from recognition of the current and future threat posed by climate change are also potent psychological stressors for individuals and communities (Clayton, 2018; Cunsolo Willox et al., 2015). Among some especially vulnerable communities, exposure to severe ecological events exacerbated by climate change combines with anxiety about future climate change impacts to generate levels of psychological distress that significantly impair key aspects of day-to-day life (Gibson, Barnett, Haslam, \& Kaplan, 2020). The challenge for researchers 
remains to further establish how, and to what degree, negative emotional responses to climate change are affecting people's mental health across broad cultural and geographical scales.

\section{Limitations and Future Directions}

Causal relationships cannot be established with the data examined in this article due to their cross-sectional nature and there are potential alternative explanations for the pattern of associations observed in our data. For example, irrespective of climate change concerns, poor sleep can arise from various lifestyle factors including job stress, alcohol consumption, smoking, insufficient physical activity and excessive use of electronic media (Hafner, Stepanek, Taylor, Troxel, \& van Stolk, 2017). Sleep is also an important determinant of mental health and a key influence on ability to regulate negative emotions (Harvey et al., 2011). Consequently, the current findings may reflect the concurrent influence of poor sleep on mental health and individuals' ability to regulate negative emotional responses to a broad range of stressors including consciousness of climate change-related risks. Further research involving experimental and longitudinal designs is needed to determine the direction of causal links between negative climaterelated emotions and sleep proposed here.

Related to the above consideration is also the question of how negative emotional responses to climate change conceptually relate to poor mental health. Negative emotions such as a sustained state of heightened worry can be indicative of an underlying mental health disorder (Hirsch \& Mathews, 2012). Thus, it can be argued that strong feelings of worry about climate change could simply be a manifestation of poor mental health. However, previous research has shown that habitual worrying about ecological problems is unrelated to pathological worry (Verplanken \& Roy, 2013). Further, worrying about climate change in particular, while being dysfunctional for some individuals, is generally associated with a suite of factors including pro-environmental values, 'green' identity and environmental threat perception that in combination indicate an adaptive pro-environmental response (Verplanken, Marks, \& Dobromir, 2020). Therefore, the hypothesized decremental effect of negative climate-related emotions on mental health is clearly justified by the existing empirical literature.

It is important to note that our study is limited by the use of a single-item measure of mental health. This measure afforded the benefit of brevity in administration of the questionnaire. However, it is impossible to determine the reliability of the measure or the degree to which it appropriately reflects the complex experiences of mental health across the range of cultural contexts represented in our study. Previous research has recorded moderate correlations between the single-item mental health measure and multi-item scales such as the K6 psychological distress scale and the mental health subscale of the short form survey (SF-12) (see Ahmad et al., 2014). However, the single-item mental health measure is not directly equivalent to established multi-item mental health scales and caution must be exercised in drawing definite conclusions from findings based on the single-item measure.

Finally, the sample obtained in our cross-national survey was based on a convenience sampling strategy rather than probability sampling of individuals within the countries represented. This means that the findings may not necessarily generalizable to the broader national populations from which these samples were drawn. The close replication of findings across the non-representative cross-national sample and the nationally-representative sample of Norwegian residents is a basis for confidence in the overall findings from the study. Nonetheless, subsequent replication with representative samples in non-Western countries is needed to further establish the relationship between negative climate-related emotions and mental health in a global context.

\section{Conclusions}

Care should be taken to not to overstate the global significance of negative climate-related emotions for mental health in the absence of substantive empirical evidence. On average, we observed a modest amount of shared variance between negative climate-related emotions and self-rated mental health among our cross-national (6\%) and representative Norwegian (3\%) samples. There are myriad situational and contextual factors that contribute to determining individuals' mental health, of which negative emotions regarding climate change may be a significant component. Yet, there are compelling theoretical and empirical indications supporting a notion that negative climate-related emotions act as a pathway for the negative mental health impacts of climate change. This notion is further supported by findings of our research which show that negative climate-related emotions are associated with insomnia symptoms and self-rated mental health across a diverse sample of individuals. Importantly, what our study most strongly reflects is the continuing need for cross-disciplinary and cross-cultural scholarship to develop more rigorous empirical assessments of the unique burden of disease that can be attributed to negative climate-related emotions in the mental health domain across the world.

Supplementary Information The online version contains supplementary material available at https://doi.org/10.1007/s12144-021-01385-4.

Data Availability The data upon which this article is based are available from the corresponding author on reasonable request.

\section{Compliance with Ethical Standards}

Conflict of Interest The authors declare no conflict of interest. 
Open Access This article is licensed under a Creative Commons Attribution 4.0 International License, which permits use, sharing, adaptation, distribution and reproduction in any medium or format, as long as you give appropriate credit to the original author(s) and the source, provide a link to the Creative Commons licence, and indicate if changes were made. The images or other third party material in this article are included in the article's Creative Commons licence, unless indicated otherwise in a credit line to the material. If material is not included in the article's Creative Commons licence and your intended use is not permitted by statutory regulation or exceeds the permitted use, you will need to obtain permission directly from the copyright holder. To view a copy of this licence, visit http://creativecommons.org/licenses/by/4.0/.

\section{References}

Ahmad, F., Jhaij, A. K., Stewart, D. E., Burghardt, M., \& Bierman, A. S. (2014). Single item measures of self-rated mental health: A scoping review. BMC Health Services Research, 14(1), 398. https://doi.org/ 10.1186/1472-6963-14-398.

Albrecht, G. (2011). Chronic Environmental Change: Emerging 'Psychoterratic' Syndromes. In Chronic Environmental Change: Emerging 'Psychoterratic' Syndromes (pp. 43-56). New York, NY: Springer. https://doi.org/10.1007/978-1-4419-9742-5_3.

Baglioni, C., Spiegelhalder, K., Lombardo, C., \& Riemann, D. (2010). Sleep and emotions: A focus on insomnia. Sleep Medicine Reviews, 14(4), 227-238. https://doi.org/10.1016/J.SMRV.2009.10.007.

Baglioni, C., Nanovska, S., Regen, W., Spiegelhalder, K., Feige, B., Nissen, C., Reynolds, C. F., \& Riemann, D. (2016). Sleep and mental disorders: A meta-analysis of polysomnographic research. Psychological Bulletin, 142(9), 969-990. https://doi.org/10.1037/ bul0000053.

Barton, K. (2013). Package "MuMIn: Multi-model inference" for R. R Package Version 1.9.5.

Bates, D., Maechler, M., Bolker, B., \& Walker, S. (2014). lme4: Linear mixed-effects models using S4 classes. R package version 1.1-6. In $R$. http://CRAN.R-project.org/package=lme4

Bay, T., \& Ergun, A. (2018). Validity and reliability of Bergen insomnia scale (BIS) among adolescents/Adolesanlarda Bergen Uykusuzluk Olceginin Gecerlik ve Guvenirligi. Clinical and Experimental Health Sciences, 8(4), 268-276 https://go.gale.com/ps/i.do?p= AONE\&sw $=w \& i s s n=24591459 \& v=2.1 \& i t=r \& i d=G A L E \%$ 7CA581249853\&sid=googleScholar\&linkaccess=fulltext.

BBC. (2019a). The mums with eco-anxiety: "I could cry all the time." BBC News. https://www.bbc.co.uk/news/uk-englandnottinghamshire-49836830

BBC. (2019b). The rise of climate change anxiety. BBC Ideas. https:// www.bbc.com/ideas/videos/are-you-suffering-from-climatechange-anxiety/p073zgqd

BBC. (2020). Climate anxiety: Survey for BBC Newsround shows children losing sleep over climate change and the environment. $C B B C$ Newsround. https://www.bbc.co.uk/newsround/51451737

Bednarek, S. (2019). Is there a therapy for climate change anxiety? Therapy Today, 30(5), 36-39.

BPS. (2018). Code of Ethics and Conduct (Vol. 21, Issue 2) (Vol. 21, pp. 134-135). British Psychological: Society. https://doi.org/10.1016/ s0315-5463(88)70754-3.

Brislin, R. W. (1970). Back-translation for cross-cultural research. Journal of Cross-Cultural Psychology, 1(3), 185-216. https://doi. org/10.1177/135910457000100301.

Burke, M., González, F., Baylis, P., Heft-Neal, S., Baysan, C., Basu, S., \& Hsiang, S. (2018). Higher temperatures increase suicide rates in the United States and Mexico. Nature Climate Change, 8(8), 723729. https://doi.org/10.1038/s41558-018-0222-x.

Carleton, T. A. (2017). Crop-damaging temperatures increase suicide rates in India. Proceedings of the National Academy of Sciences of the United States of America, 114(33), 8746-8751. https://doi.org/ 10.1073/pnas.1701354114.

Clayton, S. (2018). Mental health risk and resilience among climate scientists. Nature Climate Change, 8(4), 260-261. https://doi.org/10. 1038/s41558-018-0123-z.

Clayton, S. (2020). Climate anxiety: Psychological responses to climate change. Journal of Anxiety Disorders, 74, 102263. https://doi.org/ 10.1016/j.janxdis.2020.102263.

Clayton, S., \& Karazsia, B. T. (2020). Development and validation of a measure of climate change anxiety. Journal of Environmental Psychology, 69, 101434. https://doi.org/10.1016/j.jenvp.2020. 101434.

Clayton, S., Manning, C., Krygsman, K., \& Speiser, M. (2017). Mental health and our changing climate: impacts, implications and guidance. https://www.apa.org/news/press/releases/2017/03/ mental-health-climate.pdf

Cunsolo, A., \& Ellis, N. R. (2018). Ecological grief as a mental health response to climate change-related loss. Nature Climate Change, 8(4), 275-281. https://doi.org/10.1038/s41558-018-0092-2.

Cunsolo Willox, A., Stephenson, E., Allen, J., Bourque, F., Drossos, A., Elgarøy, S., Kral, M. J., Mauro, I., Moses, J., Pearce, T., MacDonald, J. P., \& Wexler, L. (2015). Examining relationships between climate change and mental health in the circumpolar north. Regional Environmental Change, 15(1), 169-182. https://doi.org/ 10.1007/s10113-014-0630-z.

Doherty, T, J. (2018). Individual impacts and resilience. In Psychology and Climate Change (pp. 245-266). Academic press. https://doi. org/10.1016/B978-0-12-813130-5.00010-2.

Doherty, T. J., \& Clayton, S. (2011). The psychological impacts of global climate change. American Psychologist, 66(4), 265-276. https://doi. org/10.1037/a0023141.

Evans, G. W. (2019). Projected behavioral impacts of global climate change. Annual Review of Psychology, 70(1), 449-474. https://doi. org/10.1146/annurev-psych-010418-103023.

Fagan, M., \& Huang, C. (2019). How people worldwide view climate change. https://www.pewresearch.org/fact-tank/2019/04/18/a-lookat-how-people-around-the-world-view-climate-change/

Fritze, J. G., Blashki, G. A., Burke, S., \& Wiseman, J. (2008). Hope, despair and transformation: Climate change and the promotion of mental health and wellbeing. International Journal of Mental Health Systems, 2(1), 13. https://doi.org/10.1186/1752-4458-2-13.

Gibson, K. E., Barnett, J., Haslam, N., \& Kaplan, I. (2020). The mental health impacts of climate change: Findings from a Pacific Island atoll nation. Journal of Anxiety Disorders, 73, 102237. https://doi. org/10.1016/j.janxdis.2020.102237.

Giosan, C., Glovsky, V., \& Haslam, N. (2001). The lay concept of 'mental disorder': A cross-cultural study. Transcultural Psychiatry, 38(3), 317-332. https://doi.org/10.1177/136346150103800303.

Graham, H., White, P., Cotton, J., \& McManus, S. (2019). Flood- and weather-damaged homes and mental health: An analysis using England's mental health survey. International Journal of Environmental Research and Public Health, 16(18), 3256. https:// doi.org/10.3390/ijerph16183256.

Gustafson, A., Bergquist, P., Leiserowitz, A., \& Maibach, E. (2019). A growing majority of Americans think global warming is happening and are worried. https://climatecommunication.yale.edu/ publications/a-growing-majority-of-americans-think-globalwarming-is-happening-and-are-worried/

Hafner, M., Stepanek, M., Taylor, J., Troxel, W. M., \& van Stolk, C. (2017). Why sleep matters-the economic costs of insufficient sleep: A cross-country comparative analysis. Rand Health Quarterly, 6(4), 11 http://www.ncbi.nlm.nih.gov/pubmed/28983434. 
Harvey, A. G., Murray, G., Chandler, R. A., \& Soehner, A. (2011). Sleep disturbance as transdiagnostic: Consideration of neurobiological mechanisms. Clinical Psychology Review, 31(2), 225-235. https:// doi.org/10.1016/j.cpr.2010.04.003.

Hayes, K., Blashki, G., Wiseman, J., Burke, S., \& Reifels, L. (2018). Climate change and mental health: Risks, impacts and priority actions. International Journal of Mental Health Systems, 12(1), 28. https://doi.org/10.1186/s13033-018-0210-6.

Hirsch, C. R., \& Mathews, A. (2012). A cognitive model of pathological worry. Behaviour Research and Therapy, 50(10), 636-646. https:// doi.org/10.1016/j.brat.2012.06.007.

Hunt, E. (2019). BirthStrikers: Meet the women who refuse to have children until climate change ends. The Guardian. https://www. theguardian.com/lifeandstyle/2019/mar/12/birthstrikers-meet-thewomen-who-refuse-to-have-children-until-climate-change-ends

Kielland, I, R., \& Larssen, K. (2019). De sier opp jobben, mister søvnen eller kaster opp - av klimaangst. DN. https:/www.dn.no/d2/helse/ miljo/helse/klima/de-sier-opp-jobben-mister-sovnen-eller-kasteropp-av-klimaangst/2-1-534878

Morganstein, J. C., \& Ursano, R. J. (2020). Ecological disasters and mental health: Causes, consequences, and interventions. Frontiers in Psychiatry, 11, 1. https://doi.org/10.3389/fpsyt.2020.00001.

Naher, L., Johora, F. T., Alam, N., \& Ahmed, O. (2019). Adaptation of the Bergen insomnia scale for use in Bangladesh. Bangladesh Psychological Studies, 29, 91-102 https://www.researchgate.net/ profile/Oli_Ahmed4/publication/338224130_Adaptation_of the Bergen_Insomnia_Scale_for_use_in_Bangladesh/links/ 5e08d967299bf10bc382b580/Adaptation-of-the-Bergen-InsomniaScale-for-use-in-Bangladesh.pdf.

Nugent, C. (2019). Terrified of climate change? You might have EcoAnxiety. Time. https://time.com/5735388/climate-change-ecoanxiety/

Obradovich, N., \& Migliorini, R. (2018). Sleep and the human impacts of climate change. Sleep Medicine Reviews, 42, 1-2. https://doi.org/10. 1016/J.SMRV.2018.09.002.

Obradovich, N., Migliorini, R., Mednick, S. C., \& Fowler, J. H. (2017). Nighttime temperature and human sleep loss in a changing climate. Science Advances, 3(5), e1601555. https://doi.org/10.1126/sciadv. 1601555.

Obradovich, N., Migliorini, R., Paulus, M. P., \& Rahwan, I. (2018). Empirical evidence of mental health risks posed by climate change. Proceedings of the National Academy of Sciences of the United States of America, 115(43), 10953-10958. https://doi.org/10.1073/ pnas. 1801528115.

Ogunbode, C. A., Doran, R., \& Böhm, G. (2020). Exposure to the IPCC special report on $1.5^{\circ} \mathrm{C}$ global warming is linked to perceived threat and increased concern about climate change. Climatic Change, 158(3-4), 361-375. https://doi.org/10.1007/s10584-019-02609-0.

Pallesen, S., Bjorvatn, B., Nordhus, I. H., Sivertsen, B., Hjørnevik, M., \& Morin, C. M. (2008). A new scale for measuring insomnia: The Bergen insomnia scale. Perceptual and Motor Skills, 107(3), 691706. https://doi.org/10.2466/PMS.107.3.691-706.
Rifkin, D. I., Long, M. W., \& Perry, M. J. (2018). Climate change and sleep: A systematic review of the literature and conceptual framework. Sleep Medicine Reviews, 42, 3-9. https://doi.org/10.1016/J. SMRV.2018.07.007.

Schmidt, A., Ivanova, A., \& Schäfer, M. S. (2013). Media attention for climate change around the world: A comparative analysis of newspaper coverage in 27 countries. Global Environmental Change, 23(5), 1233-1248. https://doi.org/10.1016/j.gloenvcha.2013.07. 020 .

Schneider-Mayerson, M., \& Leong, K. L. (2020). Eco-reproductive concerns in the age of climate change. Climatic Change, 163(2), 10071023. https://doi.org/10.1007/s10584-020-02923-y.

Schultz, P. W., Milfont, T. L., Chance, R. C., Tronu, G., Luís, S., Ando, K., Rasool, F., Roose, P. L., Ogunbode, C. A., Castro, J., \& Gouveia, V. V. (2014). Cross-cultural evidence for spatial bias in beliefs about the severity of environmental problems. Environment and Behavior, 46(3), 267-302. https://doi.org/10.1177/ 0013916512458579 .

Searle, K., \& Gow, K. (2010). Do concerns about climate change lead to distress? International Journal of Climate Change Strategies and Management, 2(4), 362-379. https://doi.org/10.1108/ 17568691011089891

Smith, N., \& Leiserowitz, A. (2014). The role of emotion in global warming policy support and opposition. Risk Analysis, 34(5), 937948. https://doi.org/10.1111/risa.12140.

Spielberger, C, D. (1983). State-trait anxiety inventory for adults. MindGarden.

Tschakert, P., Ellis, N. R., Anderson, C., Kelly, A., \& Obeng, J. (2019). One thousand ways to experience loss: A systematic analysis of climate-related intangible harm from around the world. Global Environmental Change, 55, 58-72. https://doi.org/10.1016/J. GLOENVCHA.2018.11.006.

Verplanken, B., \& Roy, D. (2013). "My worries are rational, climate change is not": Habitual ecological worrying is an adaptive response. PLoS One, 8(9), e74708. https://doi.org/10.1371/journal. pone. 0074708 .

Verplanken, B., Marks, E., \& Dobromir, A. I. (2020). On the nature of eco-anxiety: How constructive or unconstructive is habitual worry about global warming? Journal of Environmental Psychology, 72, 101528. https://doi.org/10.1016/j.jenvp.2020.101528.

Wang, S., Leviston, Z., Hurlstone, M., Lawrence, C., \& Walker, I. (2018). Emotions predict policy support: Why it matters how people feel about climate change. Global Environmental Change, 50, 2540. https://doi.org/10.1016/J.GLOENVCHA.2018.03.002.

Zhen, R., Quan, L., \& Zhou, X. (2018). Fear, negative cognition, and depression mediate the relationship between traumatic exposure and sleep problems among flood victims in China. Psychological Trauma: Theory, Research, Practice, and Policy, 10(5), 602-609. https://doi.org/10.1037/tra0000331.

Publisher's Note Springer Nature remains neutral with regard to jurisdictional claims in published maps and institutional affiliations. 


\section{Affiliations}

Charles Adedayo Ogunbode ${ }^{1,2}(1) \cdot$ Ståle Pallesen $^{3} \cdot$ Gisela Böhm $^{3,4} \cdot$ Rouven Doran $^{3} \cdot$ Navjot Bhullar $^{5} \cdot$ Sibele Aquino $^{6}$. Tiago Marot ${ }^{6}$ - Julie Aitken Schermer ${ }^{7} \cdot$ Anna Wlodarczyk $^{8} \cdot$ Su Lu $^{2} \cdot$ Feng Jiang $^{9} \cdot$ Katariina Salmela-Aro $^{10}$. Daniel Hanss ${ }^{11}$ - Daniela Acquadro Maran ${ }^{12} \cdot$ Rahkman Ardi $^{13} \cdot$ Razieh Chegeni $^{3} \cdot$ Hajra Tahir $^{3} \cdot$ Elahe Ghanbarian $^{14}$. Joonha Park ${ }^{15}$. Takashi Tsubakita ${ }^{15}$. Chee-Seng Tan ${ }^{16} \cdot$ Karlijn L. van den Broek $^{17,18} \cdot$ JohnBosco Chika Chukwuorji ${ }^{19}$. Kehinde Ojewumi ${ }^{20}$ - Marc Eric S. Reyes ${ }^{21}$. Samuel Lins ${ }^{22}$. Violeta Enea ${ }^{23}$ - Tatiana Volkodav ${ }^{24}$ - Tomas Sollar ${ }^{25}$. Ginés Navarro-Carrillo ${ }^{26}$ • Jorge Torres-Marín ${ }^{27} \cdot$ Winfred Mbungu $^{28} \cdot$ Charles Onyutha $^{29} \cdot$ Michael J. Lomas ${ }^{30}$

1 School of Psychology, University of Nottingham, University Park Campus, Psychology, Nottingham NG7 2RD, United Kingdom

2 School of Applied Social Sciences, De Montfort University, Hawthorn Building, The Gateway, Leicester LE1 9BH, UK

3 Department of Psychosocial Science, Faculty of Psychology, University of Bergen, Bergen, Norway

4 Department of Psychology, Inland University of Applied Sciences, Lillehammer, Norway

5 School of Psychology, University of New England, Armidale, NSW, Australia

6 Psychology Department, Pontifical Catholic University of Rio de Janeiro, Rio de Janeiro, Brazil

7 Department of Management and Organisational Studies, Faculty of Social Science, University of Western Ontario, London, ON, Canada

8 Escuela de Psicología, Facultad de Humanidades, Universidad Católica del Norte, Antofagasta, Chile

9 Central University of Finance and Economics, Beijing, China

10 Department of Educational Sciences, University of Helsinki, Helsinki, Finland

11 Department of Social Sciences, Darmstadt University of Applied Sciences, Darmstadt, Germany

12 Department of Psychology, University of Torino, Turin, Italy

13 Department of Psychology, Universitas Airlangga, Surabaya, Indonesia

14 Department of Educational Psychology and Counselling, Faculty of Psychology and Educational Sciences, University of Tehran, Tehran, Iran

15 NUCB Business School, Nagoya, Japan
16 Department of Psychology and Counselling, Faculty of Arts and Social Science, Universiti Tunku Abdul Rahman, Kampar, Malaysia

17 Copernicus Institute of Sustainable Development, Utrecht University, Utrecht, Netherlands

18 Research Centre for Environmental Economics, Heidelberg University, Heidelberg, Germany

19 Department of Psychology, University of Nigeria, Nsukka, Nigeria

20 Department of Psychology, Obafemi Awolowo University, Ife, Nigeria

21 College of Science, University of Santo Tomas, Manila, Philippines

22 Faculty of Psychology and Education Sciences, University of Porto, Porto, Portugal

23 Department of Psychology, Alexandru Ioan Cuza University of Iasi, Iaşi, Romania

24 Faculty of Pedagogy, Psychology and Communicative Studies, Kuban State University, Krasnodar, Russia

25 Department of Psychological Sciences, Faculty of Social Sciences and Healthcare, Constantine the Philosopher University in Nitra, Nitra, Slovakia

26 Department of Psychology, University of Jaén, Jaén, Spain

27 Department of Research Methods in Behavioural Sciences, University of Granada, Granada, Spain

28 Department of Engineering Sciences and Technology, Sokoine University of Agriculture, Morogoro, Tanzania

29 Department of Civil and Building Engineering, Kyambogo University, Kampala, Uganda

30 School of Health and Society, University of Salford, Salford, UK 